\title{
A National Research Agenda and the Self-understanding of Modern Universities
}

\author{
Rutger Claassen and Marcus Düwell
}

\section{Introduction}

The process of establishing a National Research Agenda (Nationale Wetenschapsagenda, NWA) that has been undertaken in the Netherlands in 2015-2016 seems to have been both a continuation and a break with the recent past in science policy. A continuation insofar as it fits with the trend of channelling research funds increasingly to certain communally prioritized research topics, instead of leaving this act of priority-setting to individual researchers. Unsurprisingly, this has elicited the usual objections by those who cherish the ideal of 'academic freedom' for the individual researcher. However, it seems to have been a break with this trend in that the community deciding the priorities was not the community of scientists themselves, nor organised private interests or private-public partnerships (as has been the case with the establishment of the Topsectoren, or NWO programmes like Socially Responsible Innovation). Instead, a radically bottom-up process was organised in which the public at large could pose its questions to scientists. One might have had the impression that this would be a moment of radical innovation, in which 'democracy meets science'.

However, appearances can be deceiving. In this chapter, we will first argue that the NWA is in fact primarily a continuation of the older practice of giving organised private interests a firmer grip on research priorities. The 'democratization' of science policy is just one of four possible justifications for setting up an NWA which we will distinguish in this essay (section 1). This raises the question of which of these justifications are justified. How should academic research be organised? And what is the role of a national research agenda in academic research?

To answer these questions, we will first give a philosophical analysis of the role of the university. Scientific research at its core is about the selfunderstanding of human beings. Academic researchers help individuals and groups to deal with the fundamental challenges of human existence and uncover possible perspectives on what it is to lead a (good) human life 
(section 2). From this perspective, we will argue that academic research needs both reflective distance from social actors and processes and reflective connectivity. Researchers need to guard their independence from society to be creative and reliable, and to develop long-term perspectives. At the same time, researchers need to establish meaningful connections to social actors and practices, because it is their human challenges and self-understanding which are ultimately at stake in research (section 3). Given these fundamental reflections, we formulate seven recommendations for agenda-setting in research policy. A thread which runs through all of these is a concern with the direct steering role that is currently given to a select group of private actors. Our plea is for a stronger steering role for the academic community itself, while at the same time establishing stronger, more permanent, and more in-depth discussion fora with a wider group of societal stakeholders, both public and private, commercial and non-profit (section 4).

\section{Setting up the National Research Agenda in the Netherlands}

The NWA experiment for Dutch universities has received much publicity. After a high-level public announcement (with the chairpersons of the NWA appearing in TV show De Wereld Draait Door and other media outlets), it began with a first round in which a significant number of possible research questions, close to 12,000, were sent in. In a next stage, these were ordered into 140 aggregated questions. On the basis of these questions, various clusters of questions - so-called routes - were formed. Examples of these are 'Resilient and Meaningful Societies', 'Brain, Cognition and Behaviour', 'Circular Economy' and 'The Sustainable Production of Healthy and Safe Food'. In the organisation of these latter stages, the so-called 'knowledge coalition', formed by representatives of various research-related parties among them the Netherlands Organisation for Scientific Research (NWO) and the Royal Academy of Arts and Sciences (KNAW), but also representatives of industry (VNO-NCW) and technology (TNO), played a leading role. In the follow-up to this process, bigger research activities have been planned under the direction of this knowledge coalition. These research activities bring together financing from the NWO and various societal and economic partners in order to form large, aggregated research activities. The effect of the clustering by the knowledge coalition will likely be that a significant amount of research money will be invested in specific directions.

The entire experiment was accompanied by a number of formal and informal meetings and discussions. Faculties, departments, research schools, 
and other academic bodies discussed how to relate to this agenda. These discussions were a continuation of debates at Dutch universities over the last few years, as a consequence of recent trends. First, there was the decision of the Dutch government of 2008 to shift funds from structural financing of the universities to heavy competitions organised at the NWO. Second, the knowledge coalition formulated in 2011 a policy that forced Dutch research organisations to invest a significant part of available research money in areas of industry that have had a specific relevance for Dutch economy in the past (Topsectoren). Third, there was a ministerial plan published in December 2014 to reorganise the NWO in such a way that barely any systematic form of self-governance in research would survive.

Discussions about research policy received new dynamics due to the protests in Amsterdam (the occupation of the Maagdenhuis) in early 2015 about the future of the Humanities and freedom in academic research. In this context, the NWA was perceived by many scholars as being yet another way of reducing universities to instruments for technological and economic innovation. Many researchers were critical and fearful of these developments. Two things were particularly striking: on the one hand, there seems to be a broad consensus amongst Dutch researchers about the importance and value of letting research follow its own logic. Only a university that can develop according to the internal dynamics of academic debate can flourish in terms of academic excellence, and can likewise respond appropriately to the needs of modern societies. On the other hand, however, there was a lack of convincing narratives about the legitimacy of such free research and about what appropriate decision procedures concerning the formulating of research priorities would be.

Against this background, the NWA plan was launched. Why would we want to have such an agenda? Of course one can have all kinds of suspicions as to which partners may be motivated to want such an agenda; one can speculate that some political parties want industry to have more influence on the research process, and one can speculate as to what the motivation of industry could be. We are aware that all kinds of interests will be at stake. But as philosophers we must discuss the legitimacy of such a process not on the basis of speculation concerning possible power interests, but rather we must first of all analyse critically whether or not there could be legitimate reasons for such a process. Various players within the process have made statements about the rationale or justification of having such an agenda. We will not reconstruct them here, but will summarise this by setting out four possible answers to the question, 'Why might we want to have an NWA?' (we cannot come up with more possible rationales for the 
legitimization of the research agenda, but we would be curious to learn whether there are more options).

A first possible aim in having a national research agenda could be a heuristic one. The public will come up with questions that researchers themselves have not thought of. It is quite probable that researchers and society at large have many interesting questions which are not addressed in current research; in fact, it would be surprising if this were not the case. So, in that sense, there could be reasons to find out what kind of questions the public may come up with. In relation to this, it may be valuable to make an inventory of what different stakeholders consider to be relevant research questions and to create links between them. We could easily see the research agenda as an attempt to form a forum in which the different research interests of various stakeholders and private persons are articulated and related to each other. One can, of course, wonder whether the enormous time pressure under which questions had to be articulated was helpful in facilitating the formation of well-formulated questions by stakeholders. In any case, we could see the NWA as a tool for mobilizing creative ideas about future research.

A second possible aim could be to mobilize additional financing for research. From this perspective the research agenda serves a merely strategic bargaining purpose. If the public come up with wildly attractive research ideas, government or private parties (such as big companies), so it is hoped, will make extra funds available. Only time will tell whether additional funding can be mobilized; at the moment it seems unlikely that government will be willing to invest more. Therefore, the hope now is primarily that there will be more substantial contributions from industry. However, this raises the problem of what the price of such co-financing from industry will be. If indeed such co-financing implies that industry will determine the research policy of the public funding of research, the price is very high. This problem leads directly to considering the next possible aim.

A third aim could be to organise a more democratic process of decisionmaking about research priorities. When the process began, some hoped (while others feared) that it would take a direct-democratic form. Indeed, everybody with an internet connection and basic Dutch language skills could submit questions. However, further in the process of forming the agenda, democracy does not play any role. The clustering of questions has been done by researchers and the follow-up activities are determined by the 'knowledge coalition'. The process is democratic insofar as the democratically legitimized Minister has initiated and approved the whole procedure, but no relevant democratic body has played a significant role in the further 
process. There was, for example, no relevant contribution from Parliament. Moreover, the knowledge coalition is not representative of civil society at large (i.e. representing different social or cultural organisations and interest groups). A broader plurality of possible stakeholders (such as representatives of artists, nature conservation organisations, advisory bodies etc.) were only involved in smaller advisory functions.

A fourth and final aim of the NWA could be to organise the process of priority setting in a more transparent way. Citizens were submitting questions, researchers were validating and clustering them, and under the guidance of the knowledge coalition but with the involvement of researchers and private partners, those clusters were transformed into research programmes. This transparency, however, is not based on in-depth analyses in terms of research desiderata, research excellence, or international research trends. Thus, one can wonder to what extent such a narrative would enhance the quality of decision-making concerning research priorities.

This concludes our brief overview of different expectations people had of the NWA. Have we missed a possible legitimating narrative? And what should we think of these expectations? Which of them are justified? Should we set research priorities democratically, or merely see such an agenda as having a heuristic or strategic goal? In an attempt to find answers to these questions, we must take a step back and first ask ourselves what the legitimate goals of research could be. This leads us to an inquiry into the 'philosophy of the university'. Only then can we come back to the more practical questions.

\section{The philosophy of academic research: practical self-understanding}

The question of what the relevance of academia is has preoccupied philosophers ever since something like methodologically organised forms of research have existed. Taking a short-cut, we can distil three valuable key aims of academic research.

First, the relevance of research lies in providing us with solutions for the fundamental challenges of human existence. Human beings have needs and, being dependent on their social and physical environments, may face many challenges in their lives. Research may help them to deal with those challenges: from the physical need for food and shelter, to combatting illnesses and resolving scarcities of energy, water, and other resources. Research in technology and medicine may seem to be of primary importance for this aim, but in fact the picture is much more diverse and complex. We do not 
know beforehand from which angle the most promising solutions can be expected to arrive. Problems of scarcity can be solved by technologies, but often solutions can also come from changes in human behaviour. Whether or not a specific technology is genuinely a solution for our problems will often depend on the cultural and political circumstances in which it is applied. Some fundamental technical changes (e.g. in the life sciences) need decades of research before they come to technical applicability. It is hard to predict to what extent those technologies really will provide significant solutions, or if they will raise more problems than they solve. Significant components of research today deal with solutions for the 'side-constraints' and consequences of earlier solutions. Prolonging life expectancy through better healthcare systems produces overpopulation. Increases in consumption, energy use, and emissions result in climate change. Whether or not the most significant solutions for all of these problems will come from the life sciences, from ICT, or from changes in the institutional and social setting we cannot say in advance. Perhaps the energy problem will be solved by the development of more sustainable forms of energy, perhaps by digital technologies that will make travelling superfluous, or perhaps we will simply change our habits in fundamental ways. It seems probable that solutions will be a combination of all these factors. However, since we do not know where solutions can be expected to come from, and since most of these research activities are premised on long-term investments, often on a global scale, it is hard to take decisions regarding research priorities solely on the basis of expectations concerning the best solutions for existential problems.

Second, we can see research as part of realising more complex social, moral, and cultural projects. Human beings do not only want to survive and be protected against illness, natural catastrophes, wars, and terrorists. They want to live lives in which they realise specific goals, projects, values, or ideals. For example, we want to live in a democratic society in which the citizens themselves legitimize power. Such a society presupposes that citizens are empowered to form political opinions of their own, are capable of articulating political views and justifying those views in political discourses, and of developing instruments for complex decision-making. Moreover, we want to live in societies that are socially just and inclusive, where people with different mental and bodily capacities and different social and cultural backgrounds can find ways of leading fulfilling lives. We want to have societies that are culturally interesting and diverse, where a variety of cultural and aesthetic forms of expression are possible. For all of these projects to be realised, we need competences from different 
academic disciplines. Here too we do not know in advance which disciplines will be particularly important for supporting their realisation. Important developments in the history of research have often come from unexpected sides. Moreover, when it comes to cultural and creative dynamics, it is crucial that we remain open to the unplanned.

Third, humans are self-reflexive beings. Whilst engaging in the projects mentioned above, they reflect upon what they are doing and what they are valuing. Humans are driven by the ambition of understanding the natural world, understanding the history of humankind, and understanding the basic conditions of their existence (such as language, culture, behaviour, emotions, and cognition). They want to understand how religion influences their interpretation of social institutions, or how their emotions and cognitions are influenced by biological processes. They want to understand how Chinese art opens up other views than Western art on the interpretation of the world. The drive to understand is not a mere extra (a 'bonus') for a fulfilling life, an indulgence of one's curiosity. It is an integral part of a fulfilling life. Human beings cannot formulate (and reformulate) the projects mentioned above if they do not reflect upon them. They need orientations for practical living. A reflectively oriented life simply is the human way of living. Now, academic research comes into the picture because it can help humans by enhancing their self-understanding. Having an adequate understanding of the world around us presupposes research about the phenomena in question, and all academic disciplines, from history to literature studies, from psychology to biology, from medicine to physics, can help in providing this knowledge. The enormous amounts of popular scientific books testify to the fact that humans eagerly absorb academic knowledge.

Moreover, self-understanding also requires a more fundamental understanding of the basis of understanding itself. If we aim at understanding, we must first know what understanding means, and what the presuppositions of understanding are. This requires an understanding of logic, hermeneutics, and ethics, which we know from the history of philosophy, in which people have thought about the possible ways of orienting ourselves in the world, and what reasons we have to assume that some of these interpretations are better than others. It is impossible not to make assumptions about the conditions of understanding. Developing a research question and a research methodology already presupposes that we can give an account of what we want to understand, and in each possible account we already make contestable presuppositions about what it means to understand something. That we make such presuppositions is not a bad thing. We are simply not capable of engaging in any research process if we do not make presuppositions. 
However, these presuppositions are always contestable, and this means that research requires self-reflexive activities in which we understand how research itself is embedded in the way we orient ourselves in the world. Hence, the self-reflexivity of human life calls for academic research, but this in turn calls for self-reflexivity within academic research itself.

To sum up: (i) humans need to live a physically stable and where possible comfortable life, but (ii) they do so in order to lead a good life, a meaningful or fulfilling life, and (iii) they need to be self-reflexive about those outlooks on their life. Now, what does all this mean for the organisation of research?

The three aims of research cannot be seen as independent from each other in practice. The first of the three aims outlined above is very often the starting point of research. But at the same time, those research activities can only be understood in the broader context of attempts to develop more complex forms of living and understanding. From a practical perspective, a stable political and economic background is required for being able to commence substantial research activities. Research does not start from nowhere, rather it is normally the case that very concrete problems motivate people to ask more systematic questions. These considerations make establishing a strict differentiation between 'curiosity-driven' research and research that is 'socially relevant' dubious, for principled reasons.

On the one hand, research is self-destructive if there is insufficient room for the internal logic of the research processes to develop. The principal reason for this has been noted above: there is inherent uncertainty in developing technical solutions as well as social, political, and economic institutions to deal with human problems and aspirations. These uncertainties in 'real life' need to be mirrored in the academic research process, so that the latter is characterized by sufficient flexibility. We cannot predict in advance which scientific solutions and directions will turn out to be promising, and which ones will turn out to be dead ends. This means that our research agenda should not be so fixed as to stifle this internal dynamics.

On the other hand, this 'internal' dynamics does not refer to a process which is contained within the walls of the university. It refers to the selfstanding dynamics of society and science co-evolving over time through mutual interactions. There is no reason to defend an ideal of the uselessness of research which would only consist of research as a pure, Platonic form of understanding (theoria, as the perception of eternal truths). The whole opposition is flawed right from the beginning. We have reasons to see research as instrumental with regard to central projects of human life in general and modern societies in particular. But at the same time, research must be seen as a much broader attempt to get a more reflexive understanding of 
the world and the self-understanding of human beings. General reflections about the presuppositions of understanding and partial contributions from various research activities to our broader understanding of the world need to be critically discussed within a broader interdisciplinary discourse on the relative merits of each to our understanding of the world. Both elements are crucial for the possibility of fulfilling central research tasks at all.

This leads us to a conclusion that we deliberately want to put in a paradoxical form: research can only fulfil its instrumental tasks if done in a context in which it is experienced as having the intrinsic value of contributing to human self-understanding. This paradox points to a tension, but not to a contradiction. It points to an agenda for organising research agendas: we need to create research policies in such a way as to honour this paradox in academic practice. With this core message in mind, we now return to our two earlier questions: should research priorities be decided by individual researchers or by a larger community of stakeholders? If it is the latter, is there a role for 'democracy' in setting such priorities?

\section{Science and society: connectivity and distance}

The proposal of seeing the aims of research as linked to the quest for human self-understanding leads to two seemingly contradictory suggestions for the institutional design of academic research. We can formulate these as the requirements for 'reflective connectivity' and 'reflective distance', respectively.

On the one hand, researchers need to be reflectively connected to a wide range of social actors, for the simple reason that it is their human needs, cultural projects, and ultimately their self-understanding that is at stake. If research relates to the aims of human life itself, by helping social actors to deal with the challenges they face, then researchers need to be wellconnected to the actors who have these aims. This may have different implications for different disciplines. The medical sciences will require persons who are willing to donate their corpses to scientific research and volunteers to test new medications. Political science will require access to the political process, for example through a willingness from politicians to give them a 'look behind the curtain'. Business studies will require cooperation with businesses to study the outcomes of different business strategies, and so on. Academic researchers function as 'second-order actors' whose activity is connected to the lives of 'first-order actors', be it their physical, economic, or political life. These connections in some cases become 
structural, and are the basis of co-funded research conducted in cooperation with societal partners. But even if they are not, such linkages are vital to the research process. This also implies that first-order actors may have unique suggestions for research questions. If something is troubling, a cause for wonder, or inspiring for a first-order actor, this is a prima facie reason for researchers to consider whether it may lead to new research.

Structurally, the academic landscape in its entirety needs to be arranged in such a way that there is high-quality research on all three levels that we have distinguished, as well as good connections between these levels. The former presupposes that research funds are allocated in a coordinated way, so that no 'gaps' emerge in the research programme that we have outlined. This requirement may conflict with an uncoordinated way of channelling funds to universities, where in practice the number of students in a given discipline determines the amount of research in that discipline. However, it may also conflict with the practice of allowing disciplines to compete for research projects, where this would make it systematically more difficult for some disciplines to get adequate funding for educating new generations of researchers. The latter requirement (connections between the levels) presupposes the organisation of an interdisciplinary dialogue. Many of the cluster questions and routes that the NWA is currently setting up should ideally evolve into platforms for such dialogues.

All in all, we can see that the research programme of enhancing human self-understanding requires a carefully crafted research landscape. It rules out the 'anything goes' policies that are sometimes associated with the idea of individual researchers' academic freedom. However, there is another side to the coin, which we propose to formulate in terms of the requirement of 'reflective distance'.

Researchers need to have reflective distance from concrete practices in order to be able to fulfil their tasks. It is the task of companies, policymakers, civil servants etc. to provide solutions to practical problems (whatever they may be). Researchers, as second-order actors, have a different task. They have to be able to distance themselves from the concrete pressures of these practices for various reasons. First of all, it is crucial that research is reliable and independent, in the sense that it ought not to be seen as a failure if a given research project does not produce the desired results. This is a central insight from the research scandals of recent years: too much pressure on the system makes it very likely that research results will be biased or even corrupted. It is crucial for an open research atmosphere that measures are taken to counterbalance this external pressure. Secondly, we want researchers to be creative and to develop perspectives on social 
problems that the practitioners could not develop themselves; otherwise it would make more sense for practitioners to develop these solutions directly. Thirdly, researchers are capable of viewing practical problems through long-term perspectives. Researchers are good at asking questions that are not present in society, they develop views that are relevant in the long run, and they come up with ideas that will have societal impact in the future. This is a strength that is complementary to that of policymakers who need to come up with quick solutions. Seeing policy problems through long-term perspectives is precisely what is missing with regard to most political problems. Finally, research should not be instrumental with regard to specific social groups or specific social ideas. It is rather a characteristic of publically financed research that it is relevant for society at large and that it discusses, in an unbiased manner, various views, ideals, and normative starting points of various partners. It is the role of researchers to critically relate to those starting points and not be dependent on normative decisions of societal partners.

These reasons for reflective distance provide a good reason for the independence of the academic community as a whole from social actors who would want to influence the research priorities of universities. However, at least to a certain extent, they also provide a good reason for giving individual researchers sufficient room for manoeuvre, since innovative strategies for reliability, creativity, and long-termism must, in the final instance, come from them. The question then becomes how the academic community can organise its own research agenda, so that it (i) does justice to its central mission of helping social actors enhance their self-understanding, and (ii) provides individual researchers with sufficient flexibility to contribute to this task.

Taking up this challenge is made more difficult by the inner dynamics of research itself. In recent decades, research has become more diversified and specialized. Over the course of the 2oth century, something akin to a generally accepted canon of relevant disciplines, or a hierarchy of accepted research topics, became increasingly contested. There no longer is a shared research culture or generally shared philosophical understanding of what good research is, nor of which methodologies or epistemic standards are appropriate. There exists a kind of local consensus within limited research communities, but there is no broadly shared understanding of basic assumptions regarding research. This implies that discussions about research priorities are a matter of dispute that cannot be settled by reference to tradition and consensus. Moreover, specialization has reached such a level that it is hardly possible for researchers to oversee broader fields in general. 
The generalist that has informed opinions about the most relevant developments in all research fields becomes the exception, most researchers are glad if they are able to well-informed on the newest developments in their own field. Finally, due to internationalization the context of research is in fact the whole world. In some research fields people are participating in cooperative research that is virtually active on a global scale. Coordination of research on a global scale, however, only happens within some selected fields; there is no structured dialogue, rather than incidental dialogue, about research priorities.

All of these factors make priority setting in research necessarily difficult. Researchers are not sufficiently well organised to deal with disagreements about research priorities in a rational way. There is a serious lack of fora for rational discourse about the integration of specialist research into broader perspectives. Discourses about rational reasons for research to develop in one direction instead of another are hardly possible if researchers are unable to oversee the relevant fields, and are at the same time always competing for research money. That research is developing in specific directions for rational reasons is the basis for the trustworthiness of academic research (and so, in the final instance, for stability in public funding of such research). The only forum where researchers make decisions about priority setting in research is within various research organisations in decisions about research projects, and in the selection of new researchers within universities. The logic of these decisions is, however, primarily concerned with the quality of the researcher, and not with the relevance of his research topics. In practice, it will not always be easy to distinguish both aspects, but in any case these decisions do not aim to decide research priorities on the basis of a systematic analysis of research desiderata, research needs, and a systematic process of weighing arguments for or against different possible research agendas. How can we do better?

\section{Organising deliberation about research priorities}

Given the need for a research process characterized by both reflective connectivity and reflective distance, we want to highlight four aspects that we think to be crucial for future debates about priority setting against the background of the NWA:

First, it is not self-evident that research priorities should be set on a $n a-$ tional level. In fact, the NWA already has several competitors. For example, the EU has an elaborate programme of research funding, addressing the 
themes that EU civil servants have drafted in conjunction with scientists. Many universities have research focus areas of their own, into which they channel funds. Research schools (stretching over various universities), private foundations sponsoring research and others are trying to influence priorities. In this landscape, it should be made clear whether the NWA is just one amongst many initiatives, or if it somehow fulfils a coordinating role. It is not very efficient, to say the least, to have the same conversations about research priorities at different levels.

Second, the process of the NWA also forces us to reflect on what it means to formulate good research questions. Research questions are not simply formulated to increase knowledge in isolated topics. Research questions should rather be directed towards the increase of understanding of a specific domain against the background of an understanding of this domain in a broader sense. We do not simply investigate specific genes; we rather develop an understanding of the functions of genes within broader theoretical outlooks on the human body, nature, and life. This implies that the development of research questions should always be embedded within broader interdisciplinary discourses about these theoretical perspectives. The fora for those discourses are highly underdeveloped; national research schools or interdisciplinary centres and the like could fulfil crucial roles in the development of new research perspectives. What we need is for researchers to have a much more active role in the development of indepth analyses about long-term research strategies, rather than selections of research questions on specific topics. This would probably presuppose new fora for these analyses. In any case, it is important for researchers to better organise themselves to be able to play a more active role in the setting of priorities.

Third, given the demand for connectivity, it is essential that there is input from the public. However, the way this was done in the NWA was rather coarse-grained. Simply asking everyone to deliver research questions leads to a process which not only generates too many questions but is also subject to manipulation (as researchers were themselves very active in submitting research questions) and it leads to many questions which are either already answered or unanswerable. In the light of our last point, it would be necessary to embed the formulation of a research question into broader theoretical discourses in order to understand how this input relates to our current understanding of those research domains. The challenge for the future is to involve citizens in a more constructive way. This will probably require more organised contacts with various social practices in which people struggle with physical, cultural, economic, and other 
challenges. Many contacts already exist; the challenge is to bring this to bear on research priority-setting in a transparent way.

Fourth, there is a problem ofrepresentativeness in the current setup of the research agenda. Apart from academic institutions, only organisations of employers (VNO and MKB) are partners in the knowledge coalition. This reinforces existing impressions that economic interests (and only those on one side of the field) are societal partners with a stake in research. Given the centrality of human self-understanding, a much broader coalition is necessary, from Amnesty International to Urgenda, from consumer organisations to the World Nature Fund. We could even make a case that political parties, as important representatives of practical views on the future of society, should be involved. However, instead of putting all of these partners in a 'steering position' (which is what the knowledge coalition does for some representatives of industry), it would be better if they were conversation partners at a functional distance from the academic community, which itself has a steering role.

Fifth, we can wonder what instruments are appropriate for engaging with the representatives of various organisations. It seems probable that the method of co-financing in specific projects is not the most productive instrument. It is much more important to establish settings where leading figures from these organisations discuss the long-term perspectives of research together with interdisciplinary groups of researchers. Joint projects make sense only if they are embedded in a more in-depth understanding of long-term perspectives. These discourses should, however, really be for analysis, and not simply brainstorming meetings, as they have been in the case of the NWA.

Sixth, a crucial question is to what extent there could be a role for democracy in this process of priority setting. It seems that Parliament and government primarily play a role when it comes to research policy if direct economic interests are at stake, or when it comes to research that is directly relevant for specific policy areas. There is, however, hardly any serious involvement of democratic institutions in the development of research priorities. It is evident that there are limits to the meaningful involvement of political institutions, not only because of questions of competence, but also for more principled reasons - after all, in the past the fight for academic freedom was one against the direct intervention of public authorities in the independence of the universities. However, if industry has an important impact in the development of research, it is strange if democratically legitimized institutions do not. This indicates that a new relationship between the roles of political institutions, societal interest groups, and the 
researchers themselves needs to be found - a new relationship that reflects the public role of universities, and at the same time ensures the academic freedom that researchers need to fulfil their public task.

Seventh, an agenda presupposes a fixed menu of items. There needs to be a more developed idea of how this impacts upon a scientific process that itself rapidly changes every day. There is a risk of 'shooting at a moving target'. If the agenda is to become a well-established part of the Dutch research process, procedures for revision and updating need to be made so that the agenda does not fossilize into an overview of yesterday's priorities.

We hope that these suggestions provide constructive proposals for reflecting upon the current process of establishing a National Research Agenda. 